\title{
Earthquake Activities Along the Strike-Slip Fault System on the Thailand-Myanmar Border
}

\author{
Santi Pailoplee* \\ Earthquake and Tectonic Geology Research Unit (EATGRU), Department of Geology, Faculty of Science, \\ Chulalongkorn University, Bangkok, Thailand
}

Received 21 August 2013, revised 11 February 2014, accepted 25 February 2014

\begin{abstract}
This study investigates the present-day seismicity along the strike-slip fault system on the Thailand-Myanmar border. Using the earthquake catalogue the earthquake parameters representing seismic activities were evaluated in terms of the possible maximum magnitude, return period and earthquake occurrence probabilities. Three different hazardous areas could be distinguished from the obtained results. The most seismic-prone area was located along the northern segment of the fault system and can generate earthquakes of magnitude 5.0,5.8, and $6.8 \mathrm{~m}_{\mathrm{b}}$ in the next 5, 10, and 50 years, respectively. The second most-prone area was the southern segment where earthquakes of magnitude 5.0,6.0, and $7.0 \mathrm{~m}_{\mathrm{b}}$ might be generated every 18,60 , and 300 years, respectively. For the central segment, there was less than 30 and $10 \%$ probability that $6.0-$ and $7.0-\mathrm{m}_{\mathrm{b}}$ earthquakes will be generated in the next 50 years. With regards to the significant infrastructures (dams) in the vicinity, the operational Wachiralongkorn dam is situated in a low seismic hazard area with a return period of around 30 - 3000 years for a $5.0-7.0 \mathrm{~m}_{\mathrm{b}}$ earthquake. In contrast, the Hut Gyi, Srinakarin and Tha Thung Na dams are seismically at risk for earthquakes of $\mathrm{m}_{\mathrm{b}} 6.4-6.5$ being generated in the next 50 years. Plans for a seismic-retrofit should therefore be completed and implemented while seismic monitoring in this region is indispensable.
\end{abstract}

Key words: Earthquake, Frequency-magnitude distribution, Return period, Probability, Thailand-Myanmar border

Citation: Pailoplee, S., 2014: Earthquake activities along the strike-slip fault system on the Thailand-Myanmar border. Terr. Atmos. Ocean. Sci., 25, 483-490, doi: 10.3319/TAO.2014.02.25.01(T)

\section{INTRODUCTION}

According to the high mountain range morphology bounding the basins along the Thailand-Myanmar border, seven hydropower dams are currently in operation in Western Thailand and another one is planned for the eastern part of Myanmar under the Hut Gyi Hydropower Project. To support the upcoming Association of Southeast Asian Nations (ASEAN), the proposed deep sea port complex mega-scheme at Tavoy, Myanmar is also being developed (Fig. 1 and Table 1).

However, based on remote sensing interpretations, including field investigations, some seismogenic faults have been proposed in the vicinity of these regions, such as the Pan Luang, Pa Pun, Mae Hong Sorn-Tak, Moei-Tongyi, Sri Sawath and Three Pagoda fault zones (Nutalaya et al. 1985; Pailoplee et al. 2009). All of these seismogenic faults are defined together as a strike-slip fault system (SSFZ) that

\footnotetext{
* Corresponding author

E-mail:Pailoplee.S@gmail.com
}

spreads southeastwards from the major strike-slip Sagaing fault zone, Central Myanmar (Fig. 1a).

The present-day SSFZ earthquake activities are confirmed by both geological and historical (including instrumental) earthquake records. The movement sense is a rightlateral strike-slip faulting in the present time. Besides the major-great earthquakes of magnitude $\left(\mathrm{M}_{\mathrm{w}}\right)$ of 7.0 - 8.0 generated by the Sagiang fault zone (Somsa-Ard and Pailoplee 2013), there have been some moderate sized earthquakes $\left(M_{w} 5.0\right.$ - 5.9) in the SSFZ. For example in 1975, an earthquake with an $\mathrm{M}_{\mathrm{w}}$ of 5.9 was generated in the Moei-Tongyi fault zone area nearby dam site no. 1. In 1983 an earthquake with a $\mathrm{M}_{\mathrm{w}}$ of 5.6 was reported along the Sri Sawath fault zone in the vicinity of dam sites no. 3 - 6 (Fig. 1b). Although the seismicity has been quiescent since 1983 , this may be a time gap in which the seismotectonic stress is accumulating. Thus, the earthquake activities in this region should be carefully investigated. 
The main aim of this study is to evaluate the earthquake activities in terms of the possible maximum magnitudes, recurrence intervals and probabilities of earthquake occurrence along the SSFZ where a large number of signifi- cant infrastructures including eight dams and one deep sea port are located (Fig. 1a and Table 1). The results should be useful for long-term earthquake mitigation plans for the public. This study serves various seismic hazard parameters (a)

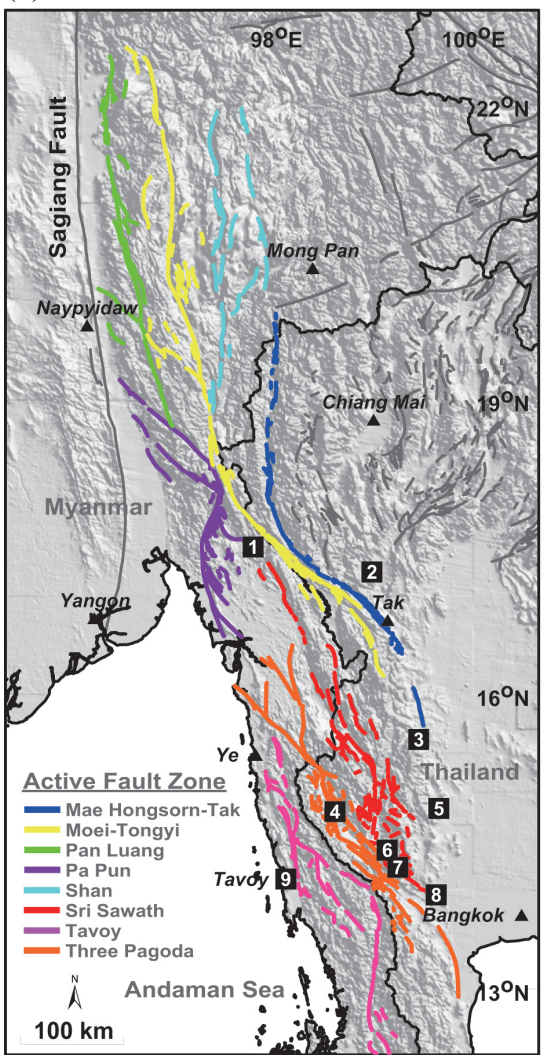

(b)

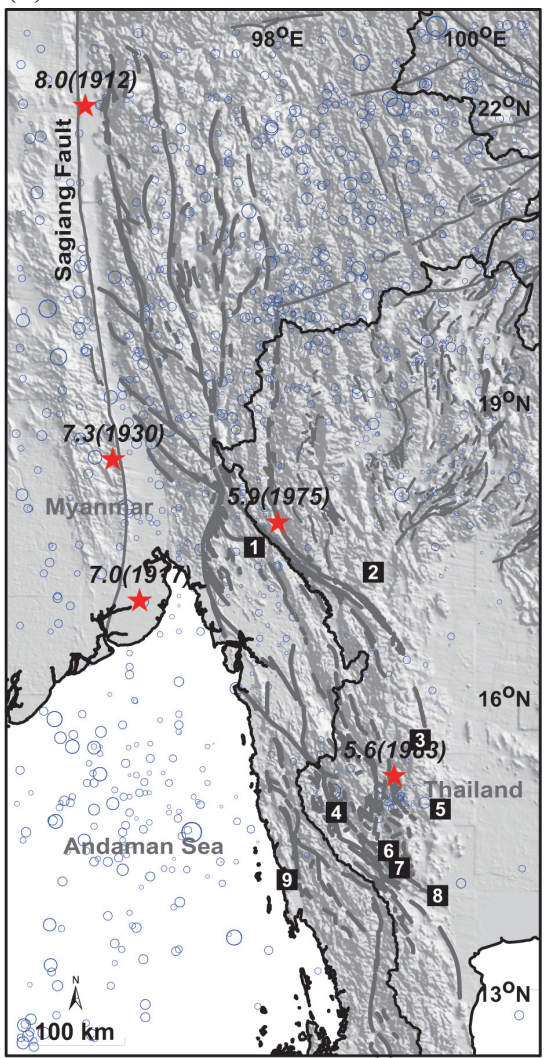

Fig. 1. Map of the Thailand-Myanmar border showing (a) the group of strike-slip fault zones (SSFZ) compiled by Nutalaya et al. (1985) and Pailoplee et al. (2009), and (b) the epicentral distributions of the completeness earthquake main shocks (i.e., after declustering) recorded during 1983 - 2009 with a magnitude range of $2.2-7.3 \mathrm{~m}_{\mathrm{b}}$, shown as circles. Stars show some of the major earthquakes as mentioned in the text. In both (a) and (b) the numbered squares indicate the locations of infrastructures operating or under construction and are equivalent to the number indicated in Table 1.

Table 1. Summary of the seismic hazard parameters representing the earthquake activities at the individual dam sites. Dam localities are shown using the same number as in Fig. 1.

\begin{tabular}{|c|c|c|c|c|c|c|c|c|c|c|}
\hline \multirow{2}{*}{ No. } & \multirow{2}{*}{ Name } & \multicolumn{3}{|c|}{ Possible maximum magnitude in $\mathrm{t}$ Yrs } & \multicolumn{3}{|c|}{ Return period of magnitude $\left(\mathbf{m}_{b}\right)$} & \multicolumn{3}{|c|}{ Probability of magnitude $\geq m_{b}$ in 50 Yrs } \\
\hline & & 5 Yrs & 10 Yrs & 50 Yrs & 5.0 & 6.0 & 7.0 & 5.0 & 6.0 & 7.0 \\
\hline 1 & Hut Gyi Dam & 4.8 & 5.9 & 6.4 & 14 & 56 & 224 & 97 & 59 & 20 \\
\hline 2 & Bhumibol Dam & - & - & - & - & - & - & - & - & - \\
\hline 3 & Tab Salao Dam & 4.6 & 5.7 & 6.2 & 18 & 74 & 301 & 93 & 49 & 15 \\
\hline 4 & Wachiralongkorn Dam & 4.5 & 5.2 & 5.5 & 33 & 317 & 3003 & 78 & 15 & 2 \\
\hline 5 & Kra Seaw Dam & 4.6 & 5.7 & 6.2 & 18 & 74 & 301 & 93 & 49 & 15 \\
\hline 6 & Srinakarin Dam & 4.6 & 6.0 & 6.5 & 15 & 52 & 175 & 96 & 62 & 25 \\
\hline 7 & Tha Thung Na Dam & 4.6 & 6.0 & 6.5 & 15 & 52 & 175 & 96 & 62 & 25 \\
\hline 8 & Mae Klong Dam & - & - & - & - & - & - & - & - & - \\
\hline 9 & Tavoy Deep Seaport & - & - & - & - & - & - & - & - & - \\
\hline
\end{tabular}


required by the International Commission on Large Dams (ICOLD 1983, 1989) which are convenient for dam site seismic retrofitting.

\section{DATA AND COMPLETENESS}

The dataset used in this study was based upon earthquake records obtained from the three earthquake catalogues, namely the Incorporated Research Institutions for Seismology, the US National Earthquake Information Center and the Thai Meteorological Department. The composite catalogue contained around 7000 earthquake events recorded within the study area during $1964-2013$. The earthquake magnitudes were reported in the range of $1.0-7.3$, but in the different recognizing scales of the $\mathrm{M}_{\mathrm{W}}$, body-wave magnitude $\left(\mathrm{m}_{\mathrm{b}}\right)$, surface-wave magnitude $\left(\mathrm{M}_{\mathrm{S}}\right)$ and local magnitude $\left(\mathrm{M}_{\mathrm{L}}\right)$. Although the $\mathrm{M}_{\mathrm{W}}$, which is derived from seismic moments is physically more meaningful than the other scales (Kramer 1996), minor changes in the other scales to the most reported $\mathrm{m}_{\mathrm{b}}$ would be the most accurate approach. Therefore, to homogenize the different magnitude scales the earthquake reports in the magnitude scale of $M_{w}, M_{S}$ or $M_{L}$ were converted to $\mathrm{m}_{\mathrm{b}}$ using the empirical relationships contributed by Pailoplee et al. (2009).

For screening the earthquake main shocks, which directly represents the seismotectonic activities, the $\mathrm{m}_{\mathrm{b}}$ homogenized earthquake catalogue was then declustered using the assumption of Gardner and Knopoff (1974). In total 2080 events from the initial 7000 events were defined as the main shocks and selected. In order to avoid the impact of man-made seismicity (e.g., Wyss 1991; Zúñiga and Wiemer 1999), the constant rates of seismicity in the individual magnitude range were then checked using the GENAS algorithm (Habermann 1983, 1987) implemented in the ZMAP program (Wiemer 2001). This revealed that the seismicity rates of earthquakes with a magnitude of $2.2-7.3 \mathrm{~m}_{\mathrm{b}}$ were constant throughout the period 1983 - 2009. Thus, a final completeness of 1440 main shock events between 1983 - 2009 were recognized as the most effective seismic data and then used for this qualitative seismic investigation. Figure $1 \mathrm{~b}$ shows the epicentral distribution of the completeness earthquake data used in this seismicity study.

\section{EARTHQUAKE ACTIVITIES}

Based on Ishimoto and Iida (1939) and Gutenberg and Richter (1944), the frequency of earthquake occurrence per year $(N)$ at an individual magnitude level equal to or larger than $M$ is related to the frequency-magnitude earthquake distribution (FMD) via Eq. (1);

$$
\log (N)=a-b M \text { or } \ln (N)=\ln \alpha-\beta M
$$

where $a$ and $b$ are positive constants that vary in any spe- cific time and space of interest and the parameters $\alpha$ and $\beta$ are related to the a- and b-values as expressed in Eq. (2), respectively;

$\alpha=\exp [a \ln (10)]$

Yadav et al. (2011) previously proposed an effective methodology and equations for evaluating the earthquake activities of a bulk seismic source zone using the constant FMD a- and b-values. Thereafter, Pailoplee et al. (2013) attempted to spatially analyze the earthquake activities in detail using the concept of Yadav et al. (2011). Using the same approach here, the study area was gridded with $0.5^{\circ} \times 0.5^{\circ}$ spacing. In each individual grid node the earthquake events located within a $75-\mathrm{km}$ radius from the node were used to plot the FMD and the a- and b-values were determined on a node by node basis based on the entire-magnitude-range method (Woessner and Wiemer 2005). In order to ascertain the reliability of the obtained a- and b-values, the goodness of fit (\%), computing the difference between the observed FMD and a synthetic distribution, was also evaluated. According to Wiemer and Wyss (2000), the more incomplete of reporting seismicity data used, i.e., higher magnitude of completeness (Mc; Woessner and Wiemer 2005), the higher difference between observed FMD and a synthetic distribution leading to the lower goodness of fit. The a- and b-values, including the percent of goodness of fit, of each individual grid node were contoured and mapped, respectively (Fig. 2). However, due to the lack of earthquake data, FMD plots of some segments of the SSFZ could not be performed.

In this study area the a-value ranged from $1.4-4.3$ (Fig. 2a), and the b-value ranged from 0.45 - 1.13 (Fig. 2b). With respect to the regional distribution three contrasting zones of different a-value ranges were evident. The northern segment, where the northern Moei-Tongyi, northern Mae Hong Sorn-Tak and Shan fault zones are delineated, had the highest comparative a-values being in the range of $2.3-4.3$. The central segment, containing the Pa Pun, southern MoeiTongyi and central Mae Hong Sorn-Tak fault zones had avalues of around 1.7 - 2.6. Finally, there was also a small region of the Sri Sawath and Three Pagoda fault zones in the southern segment with a-value ranges around $1.4-1.7$ (Fig. 2a).

In order to constrain the obtained maps, the FMD plots were prepared for three representative areas (Fig. 3). For example, at the western part of the Mong Pan close to the Moei-Tongyi fault zone (point a in Fig. 2), the a- and b-values were 4.30 and 1.13 , respectively, whereas at Hut Gyi dam, eastern Myanmar (point b in Fig. 2), the a- and b-values were 1.87 and 0.60 , respectively, and at western Thailand (point c in Fig. 2), they were 1.86 and 0.56 , respectively, (Fig. 3c). Empirically, in the seismological meaning, 
the higher the a-value the higher the entire seismicity rate. Thus, these relative a-values imply that the seismicity at the western region of Mong Pan is higher than that at Hut Gyi dam and western Thailand, respectively. In contrast, lower bvalues imply seismologically a lower ratio of small-to-large size earthquakes. Thus, the lower the b-value the higher the possibility to generate a large earthquake. As a result, the area around western Thailand might generate a larger earthquake than that at Hut Gyi dam and the western region of Mong Pan, respectively. The calculated of goodness fit was around a $70-90 \%$ probability of confidence, with a good correlation between the observed data and the regression line (Fig. 2c), and so the obtained a- and b-values (Figs. 2a and b) are likely to be reliable and reasonably accurate.

\subsection{Possible Maximum Magnitude}

According to Yadav et al. (2011), the $\alpha$ - and $\beta$-values obtained from the FMD imply the level of maximum earthquake magnitude capable of being generated in an individual (a)

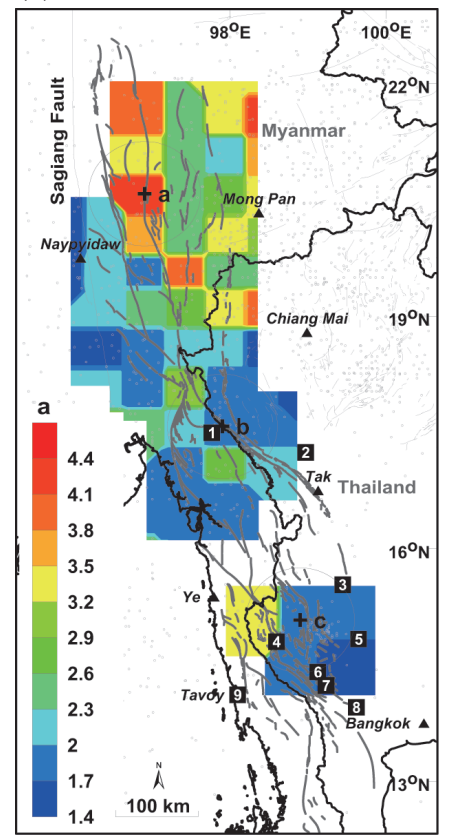

(b)

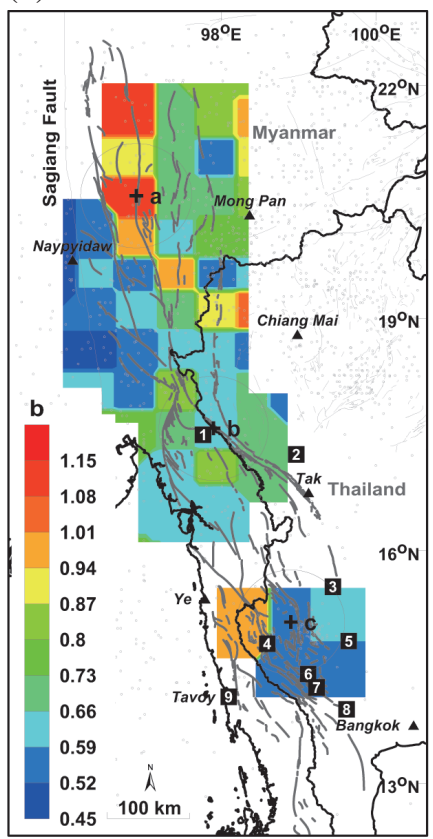

(c)

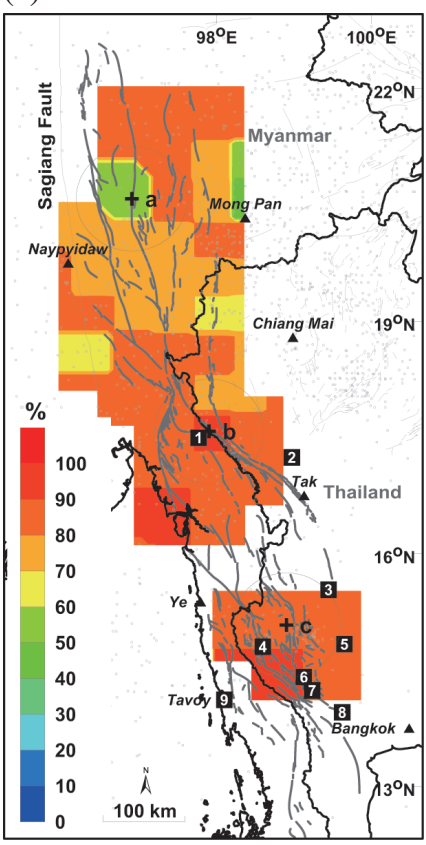

Fig. 2. Map of the Thailand-Myanmar border in the region of the SSFZ showing the spatial distributions of the constant value analyzed from the FMD plots. (a) a-value, (b) b-value and (c) the goodness of fit (\%) of the FMD. Circles indicate the 150-km radius from three demonstration areas $(\mathrm{a}-\mathrm{c})$, where the FMD plots are illustrated in Fig. 3. Numbered squares indicate the locations of infrastructures operating or under construction and are equivalent to the number indicated in Table 1.

(a) Western of Mong Pan

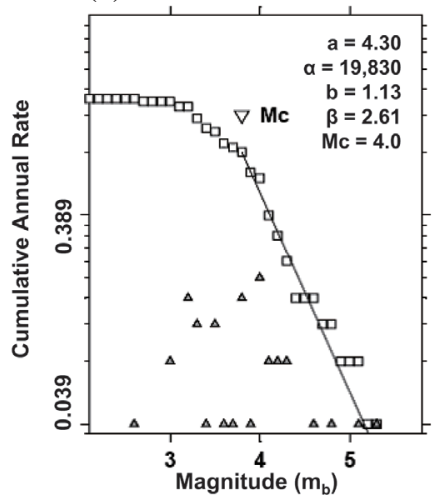

(b) Hut Gyi Dam

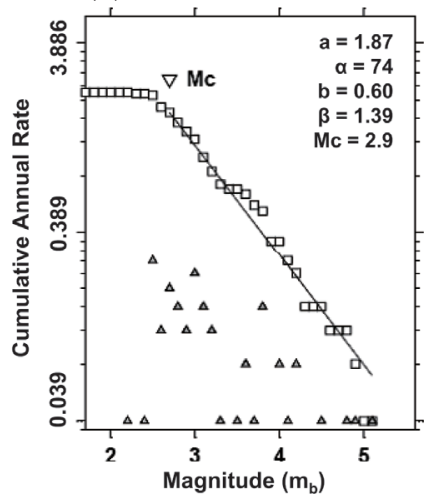

(c) Western Thailand

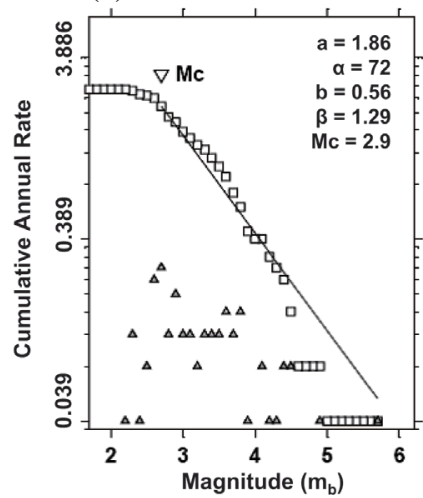

Fig. 3. FMD plots of the earthquakes located within a 150-km radius from the three specific areas shown in Fig. 2 ,i.e., (a) Western of Mong Pan, (b) Hut Gyi Dam, and (c) Western Thailand. Triangles are the number of earthquakes of each individual magnitude; squares are the cumulative number of earthquakes equal to or larger than each magnitude. Solid lines are the best-fit linear regression. Mc is defined as the magnitude of completeness (Woessner and Wiemer 2005). 
area. Using the $\alpha$ - and $\beta$-values, the possible maximum earthquake magnitude $\left(u_{t}\right)$ that could be generated within the next $t$ years can be determined via Eq. (3),

$u_{t}=\frac{\ln (\alpha t)}{\beta}$

For the SSFZ at the Thailand-Myanmar border, the a- and b-values (Fig. 2) were converted spatially to the $\alpha$ and $\beta$-values using the relationships in Eq. (2). The possible maximum magnitude that might be generated in the next 5 , 10, and 50 years was estimated and mapped (Fig. 4).

From the a-values derived in section 3, earthquakes can be generated at the central segment with a magnitude smaller of $4.0 \mathrm{~m}_{\mathrm{b}}$ in the next 5 years. In contrast, in the northern segment the maximum possible earthquake was of a magnitude of $4.2-5.0,4.6-5.8$, and $5.8-6.8 \mathrm{~m}_{\mathrm{b}}$ in the next 5,10 , and 50 years time span, respectively. The earthquake activities along the southern segment are lower than the northern segment with a smaller maximum earthquake magnitude of around 4.0 - 4.4, 4.4 - 5.0, and $5.0-6.2 \mathrm{~m}_{\mathrm{b}}$ in the next 5,10 , and 50 years, respectively (Fig. 4).

Comparing the dam sites (Table 1), the Hut Gyi, Srinakarin and Tha Thung Na dams (nos. 1, 6, and 7) is liable for an earthquake with a possible magnitude of up to $4.6-6.5 \mathrm{~m}_{\mathrm{b}}$ in the next 5 - 50 years. In contrast, the Wachiralongkorn dam (no. 4) is likely to be subject to a smaller earthquake with a magnitude of up to $5.5 \mathrm{~m}_{\mathrm{b}}$ in the next 50 years. The other dams, i.e., Tab Salao and Kra Seaw dams (nos. 3 and
5), recognized here might be subject to an earthquake of a magnitude of 4.6, 5.7, and $6.2 \mathrm{~m}_{\mathrm{b}}$ in the next 5,10 , and 50 years, respectively (Table 1).

\subsection{Return Period of Earthquake}

Yadav et al. (2011) also proposed the effective relationship between the constant values of FMD and the earthquake return period (in years). The return period $\left(T_{M}\right)$ of a specific magnitude $M$ can be estimated using the $\alpha$ - and $\beta$-values via Eq. (4) (Yadav et al. 2011).

$T_{M}=\frac{\exp (\beta M)}{\alpha}$

Mapping the return period of earthquakes with magnitudes of $5.0-7.0 \mathrm{~m}_{\mathrm{b}}$, which are recognized as hazardous earthquakes, revealed three principal hazard zones (Fig. 5), which agrees with the possible magnitude maps in Fig. 4. Beside the Moei-Tongyi fault zone, most of the northern segment of SSFZ revealed comparative short return periods less than 9,60, and 300 years for earthquake magnitudes of 5.0, 6.0, and $7.0 \mathrm{~m}_{\mathrm{b}}$, respectively. Whilst the Moei-Tongyi fault zone, the return periods range differently around 25 - 24, 90 - 300, and 900 - 1500 years. For the central segment, the return period was around $18-30,90-180$, and 450 - 750 years for earthquakes with a magnitude of 5.0, 6.0 , and $7.0 \mathrm{~m}_{\mathrm{b}}$, respectively. For the southern part, the return periods were slightly shorter at around $6-18,30-60$, (a)

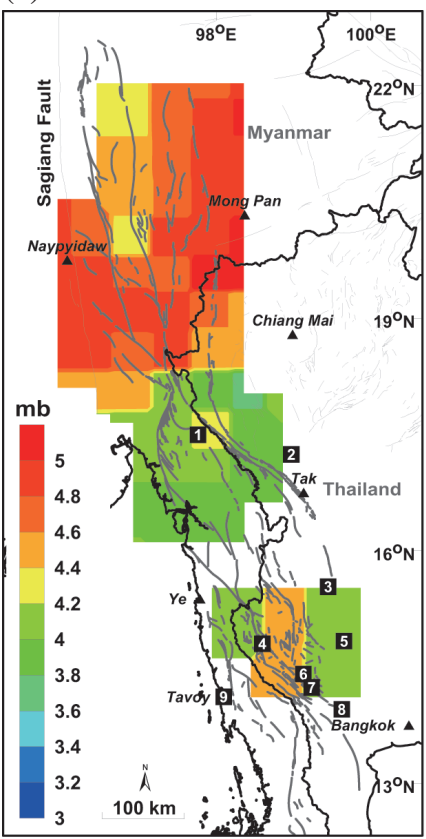

(b)

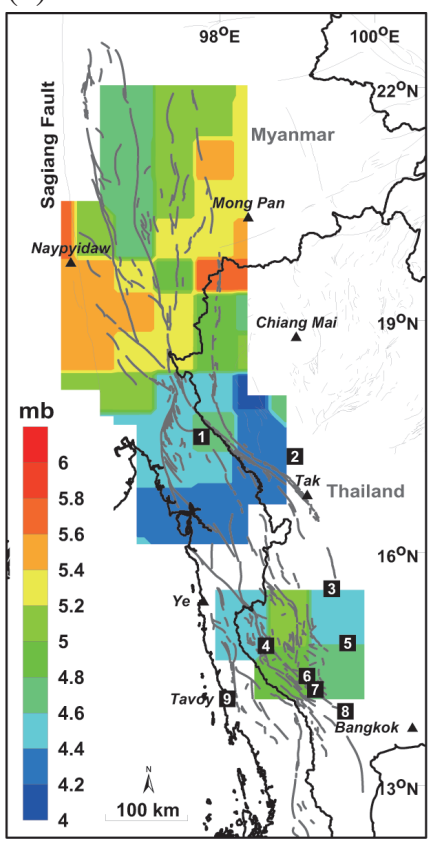

(c)

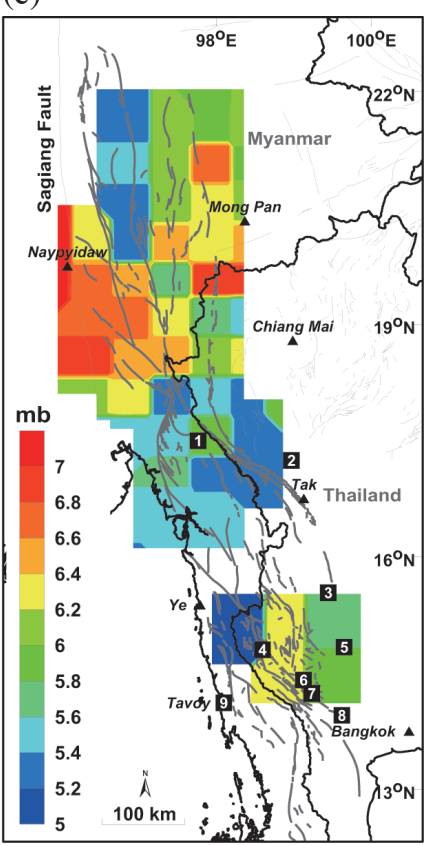

Fig. 4. Map of the Thailand-Myanmar border showing the spatial variations of the possible maximum magnitude of earthquakes that might be generated in a time span of (a) 5 , (b) 10 , and (c) 50 years. Numbered squares indicate the locations of infrastructures operating or under construction and are equivalent to the number indicated in the Table 1. 
(a)

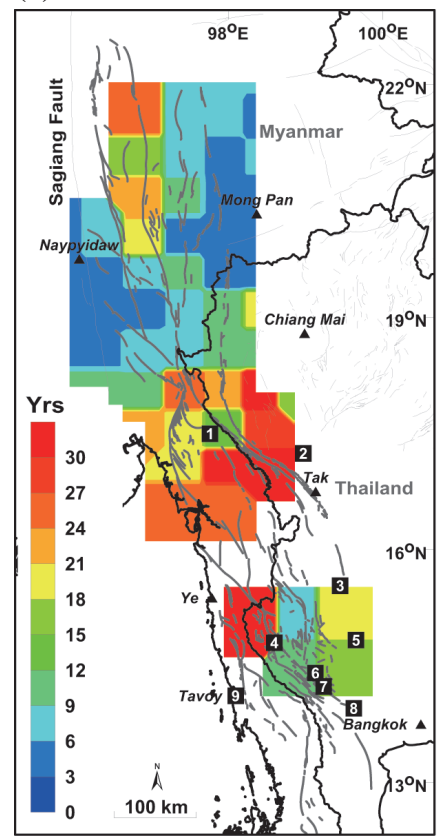

(b)

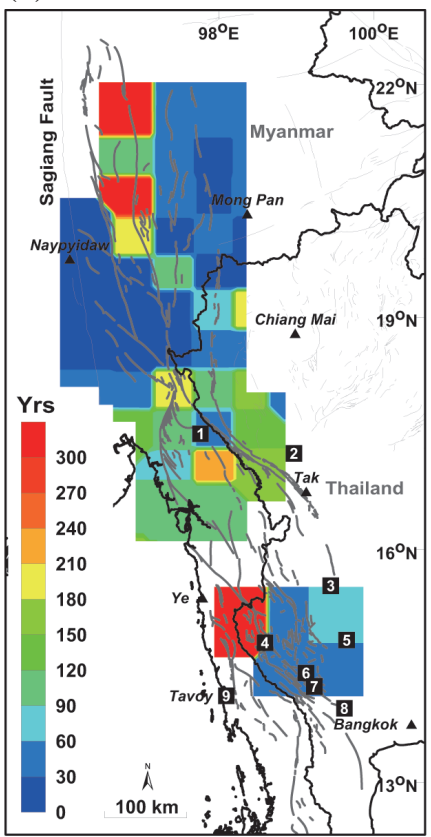

(c)

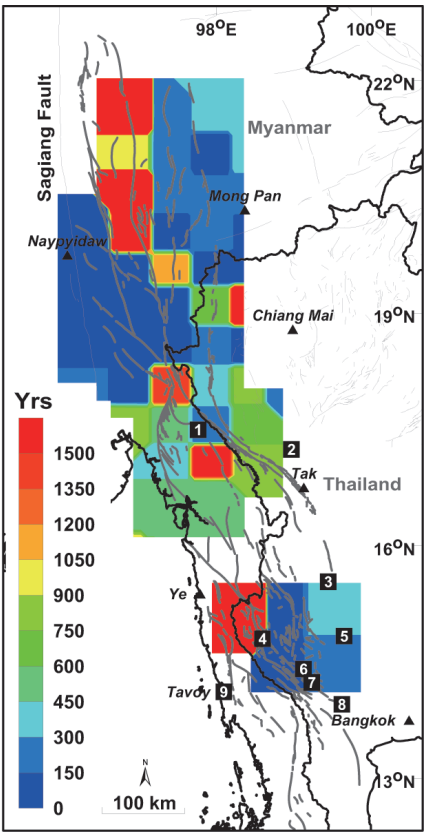

Fig. 5. Map of the Thailand and Myanmar border at the region of the SSFZ showing the recurrence interval of the individual magnitude level of interest (a) 5.0, (b) 6.0, and (c) $7.0 \mathrm{~m}_{\mathrm{b}}$. Numbered squares indicate the locations of infrastructures operating or under construction and are equivalent to the number indicated in Table 1 .

and 150 - 300 years for the earthquake magnitudes of 5.0, 6.0 , and 7.0 , respectively.

With regard to specific dam sites (Table 1), the 30 - 3000 return periods for earthquakes of $5.0-7.0 \mathrm{~m}_{\mathrm{b}}$ at Wachiralongkorn dam indicated that the dam is most likely to be safe. In contrast, the Hut Gyi, Srinakarin and Tha Thung Na dams had an estimated return period of $175-225$ years for a $7.0 \mathrm{~m}_{\mathrm{b}}$ earthquake, and $14-15$ and 52 - 56 years for a 5.0 and $6.0 \mathrm{~m}_{\mathrm{b}}$ earthquake, respectively.

\subsection{Probability of Earthquake Occurrence}

The $\alpha$ - and $\beta$-values can be also applied to express the probability of an earthquake occurrence, $P_{t}(M)$, in any time period and magnitude of interest (Yadav et al. 2011), using Eq. (5),

$$
P_{t}(M)=1-\exp [-\alpha t \cdot \exp (-\beta M)]
$$

The mapped probabilities (\%) of an earthquake with $\mathrm{m}_{\mathrm{b}} 5.0-7.0$ that might occur in the next 50 years (Fig. 6) revealed that in the most hazardeous zone in the northern segment there was an around $60-90$ and $20-50 \%$ probability of an earthquake with magnitude 6.0 and $7.0 \mathrm{~m}_{\mathrm{b}}$, respectively. In contrast, the central segment including MoeiTongyi fault zone had less than a 30 and $10 \%$ probability of a $m_{b}-6.0$ and 7.0 earthquake in 50 years, while the southern segment had $40-70$ and $10-40 \%$ probabilites of a $m_{b}-6.0$ or 7.0 earthquake in the next 50 years. Meanwhile, the prob- abilities of a $m_{b}-5.0$ earthquake were more than $70 \%$ for the whole of the SSFZ.

With respect to the individual dam sites (Table 1), the Hut Gyi, Srinakarin and Tha Thung Na dams, which is located in one of the most seismic-prone areas, had a $96-97$, $59-62$, and $20-25 \%$ probability of an earthquake with a magnitude of $5.0,6.0$, and $7.0 \mathrm{~m}_{\mathrm{b}}$, respectively, in the next 50 years. In contrast, the Wachiralongkorn dam, which is located in a seismically quiescent area (at least in the next 50 years), had only $2 \%$ probability of a $7.0 \mathrm{~m}_{\mathrm{b}}$ earthquake in the next 50 years.

For detailed clarification of the earthquake hazard, the probabilities of earthquake occurrences was investigated carefully for each of the six dams for which suitable and sufficient seismic activity records were available. Considering an earthquake magnitude of between $4.0-7.0 \mathrm{~m}_{\mathrm{b}}$ in a time span of 10, 50, and 100 years, respectively, the Hut Gyi, Srinakarin and Tha Thung Na dams had a $40 \%$ probability of an earthquake with $m_{b} 7.0$ occurring in the next 100 years (Fig. 7), whereas the Wachiralongkorn dam showed less than a $10 \%$ probability of an earthquake of $m_{b} 7.0$ occurring.

\section{DISCUSSION AND CONCLUSION}

The present-day earthquake activities were investigated along the SSFZ on the Thailand-Myanmar border. The data used for analysis was derived from the earthquake catalogue compiled by various agencies and was magnitude homogenized to the $m_{b}$ scale, foreshock-aftershock declustered, 
and carefully screened for man-made seismicity artifacts to obtain the completeness earthquake dataset of 1440 main shock events from 1983 - 2009 representing the present-day seismotectonic activities. From the derived spatial FMD the constant a- and b-values were mapped and used to determine the seismic hazard parameters of the possible maximum (a)

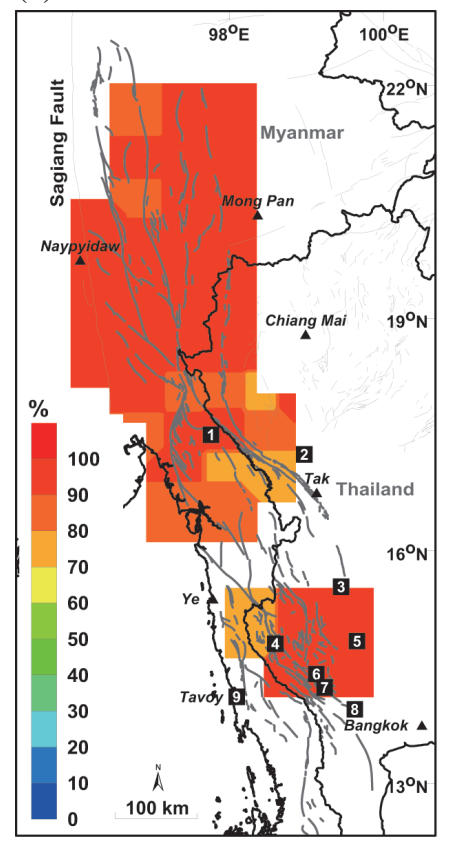

(b)

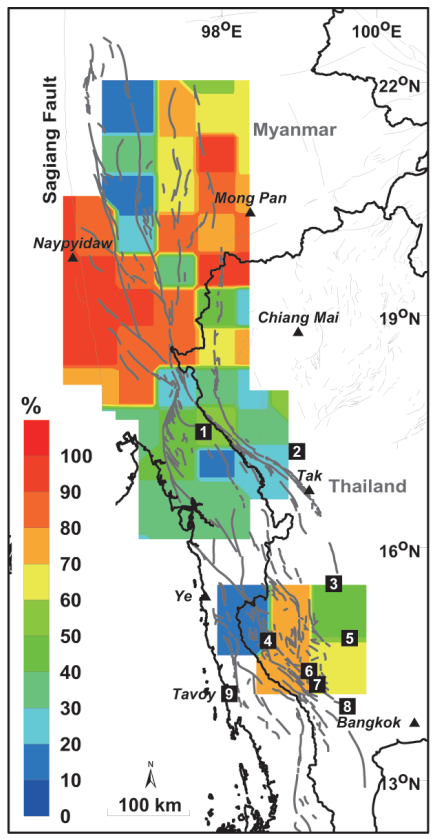

(c)

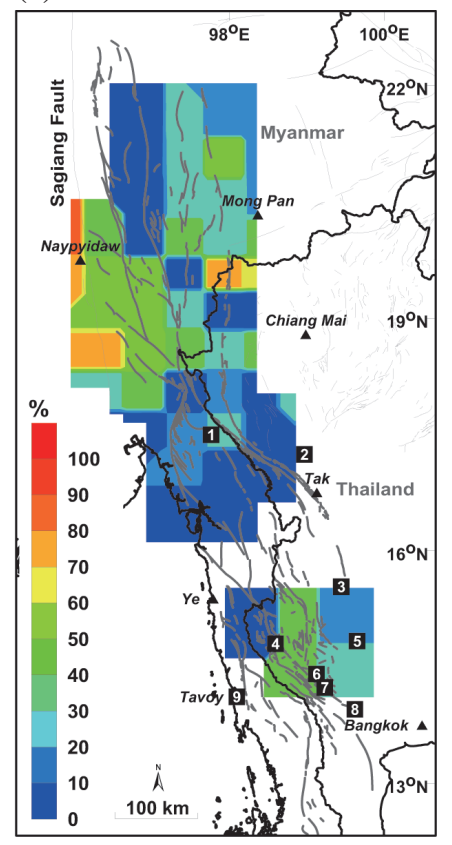

Fig. 6. Map of the Thailand-Myanmar border in the SSFZ study region showing the spatial distributions of the probabilities of earthquake occurrences for earthquakes with a magnitude of (a) 5.0, (b) 6.0, and (c) $7.0 \mathrm{~m}_{\mathrm{b}}$ in the next 50 years. Numbered squares indicate the locations of infrastructures operating or under construction and are equivalent to the number indicated in Table 1.
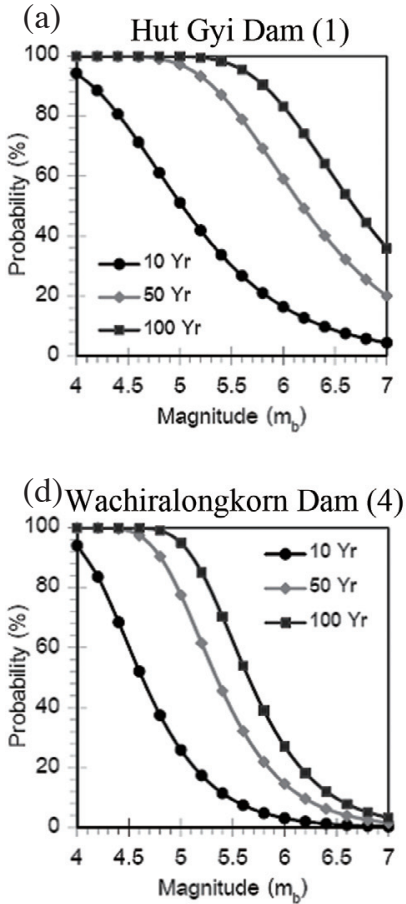

(b)

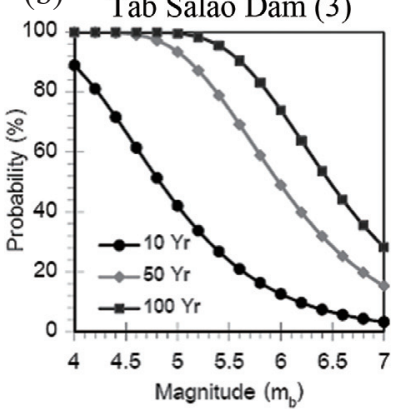

(e) Srinakarin Dam (6)

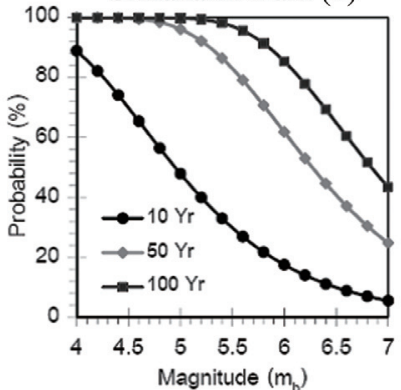

(c) Kra Seaw Dam (5)

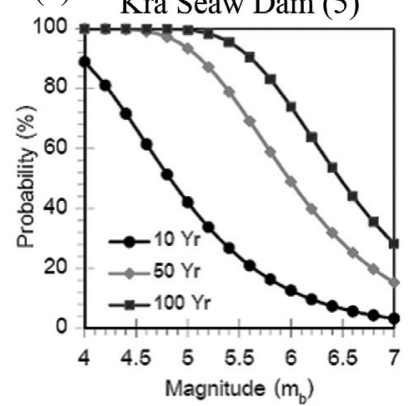

(f) Tha Thung Na Dam (7)

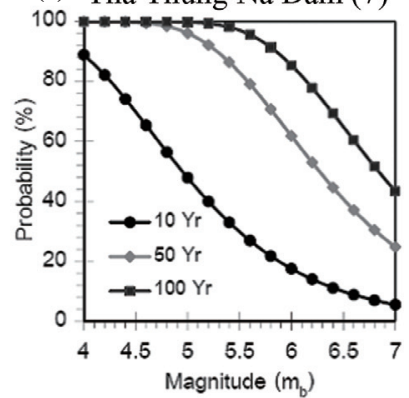

Fig. 7. The probability-magnitude curves for the six dam sites nearby the SSFZ (those for which suitable and sufficient seismic activity records were available), showing the probability of occurrence of an earthquake of $\mathrm{m}_{\mathrm{b}} 4.0-7.0$ in the next 10, 50, and 100 years. (a) Hut Gyi Dam, (b) Tab Salao Dam, (c) Kra Seaw Dam, (d) Wachiralongkorn Dam, (e) Srinakarin Dam, and (f) Tha Thung Na Dam. 
magnitude, return period and the probabilities of occurrence of earthquakes.

From the obtained results, three principal different hazardous areas were found. The most seismic-prone area was located along the northern segment of the SSFZ, which can generate a likely maximum earthquake of magnitude up to $5.0,5.8$, and $6.8 \mathrm{~m}_{\mathrm{b}}$ in the next 5,10 , and 50 years, respectively. The southern segment was less active with a maximum earthquake of $\mathrm{m}_{\mathrm{b}} 5.0,6.0$, and 7.0 being generated every 18 , 60 , and 300 years, respectively, whilst the central segment and the Moei-Tongyi fault zone was defined as a low seismic zone, with a less than 30 and $10 \%$ probability of an earthquake of magnitude 6.0 and $7.0 \mathrm{~m}_{\mathrm{b}}$ in next 50 years.

With regard to the significant infrastructures in the area (dams), the area surrounding the operational Wachiralongkorn dam showed a low seismic hazard with a return period of earthquakes with $m_{b} 5.0-7.0$ of around $30-3000$ years. In contrast, the Hut Gyi, Srinakarin and Tha Thung Na dams are at a high risk with an earthquake of $\mathrm{m}_{\mathrm{b}} 6.4-6.5$ likely to be generated in the next 50 years. Thus, a plan of seismic-retrofit should be completed and seismic monitoring in these cases is indispensable.

Acknowledgments This research has been supported by the Ratchadaphiseksomphot Endowment Fund 2013 of Chulalongkorn University (CU-56-443-CC). Thanks are also extended to T. Pailoplee for the preparation of the draft manuscript. We thank the Publication Counseling Unit (PCU), Faculty of Science, Chulalongkorn University, for a critical review and improved English. We acknowledge the thoughtful comments and suggestions by C.-CH. Chen (Editor), M.-L. Chen (Assistant Editor), C.-H. Chan and anonymous reviewers who enhanced the quality of this manuscript significantly.

\section{REFERENCES}

Gardner, J. K. and L. Knopoff, 1974: Is the sequence of earthquakes in Southern California, with aftershocks removed, Poissonian? Bull. Seismol. Soc. Am., 64, 1363-1367.

Gutenberg, B. and C. F. Richter, 1944: Frequency of earthquakes in California. Bull. Seismol. Soc. Am., 34, 185188.

Habermann, R. E., 1983: Teleseismic detection in the Aleutian Island Arc. J. Geophys. Res., 88, 5056-5064, doi: 10.1029/JB088iB06p05056. [Link]

Habermann, R. E., 1987: Man-made changes of seismicity rates. Bull. Seismol. Soc. Am., 77, 141-159.

ICOLD, 1983: Seismicity and Dam Design, International Commission on Large Dams, Bulletin 46, 121 pp.
ICOLD, 1989: Selecting Seismic Parameters for Large Dams, International Commission on Large Dams, Bulletin $72,73 \mathrm{pp}$.

Ishimoto, M. and K. Iida, 1939: Observations of earthquakes registered with the microseismograph constructed recently. Bull. Earthq. Res. Inst., 17, 443-478.

Kramer, S. L., 1996: Geotechnical Earthquake Engineering, Prentice Hall, Inc., Upper Saddle River, New Jersey, $653 \mathrm{pp}$.

Nutalaya, P., S. Sodsri, and E. P. Arnold, 1985: Series on Seismology, Volume II - Thailand, Technical report, Southeast Asia Association of Seismology and Earthquake Engineering, 403 pp.

Pailoplee, S., Y. Sugiyama, and P. Charusiri, 2009: Deterministic and probabilistic seismic hazard analyses in Thailand and adjacent areas using active fault data. Earth Planets Space, 61, 1313-1325.

Pailoplee, S., P. Channarong, and V. Chutakositkanon, 2013: Earthquake activities in the Thailand-LaosMyanmar Border region: A statistical approach. Terr. Atmos. Ocean. Sci., 24, 721-730, doi: 10.3319/ TAO.2013.04.26.01(T). [Link]

Somsa-Ard, N. and S. Pailoplee, 2013: Seismic hazard analysis for Myanmar. J. Earthq. Tsunami., 7, doi: 10.1142/S1793431113500292. [Link]

Wiemer, S., 2001: A software package to analyze seismicity: ZMAP. Seismol. Res. Lett., 72, 373-382, doi: 10.1785/ gssrl.72.3.373. [Link]

Wiemer, S. and M. Wyss, 2000: Minimum magnitude of completeness in earthquake catalogs: Examples from Alaska, the western United States, and Japan. Bull. Seismol. Soc. Am., 90, 859-869, doi: 10.1785/0119990114. [Link]

Woessner, J. and S. Wiemer, 2005: Assessing the quality of earthquake catalogues: Estimating the magnitude of completeness and its uncertainty. Bull. Seismol. Soc. Am., 95, 684-698, doi: 10.1785/0120040007. [Link]

Wyss, M., 1991: Reporting history of the Central Aleutians Seismograph Network and the quiescence preceding the 1986 Andreanof Island earthquake. Bull. Seismol. Soc. Am., 81, 1231-1254.

Yadav, R. B. S., J. N. Tripathi, D. Shanker, B. K. Rastogi, M. C. Das, and V. Kumar, 2011: Probabilities for the occurrences of medium to large earthquakes in northeast India and adjoining region. Nat. Hazards., 56, 145-167, doi: 10.1007/s11069-010-9557-y. [Link]

Zúñiga,F. R. and S. Wiemer, 1999: Seismicity patterns: Are they always related to natural causes? Pure Appl. Geophys., 155, 713-726, doi: 10.1007/s000240050285. [Link] 